
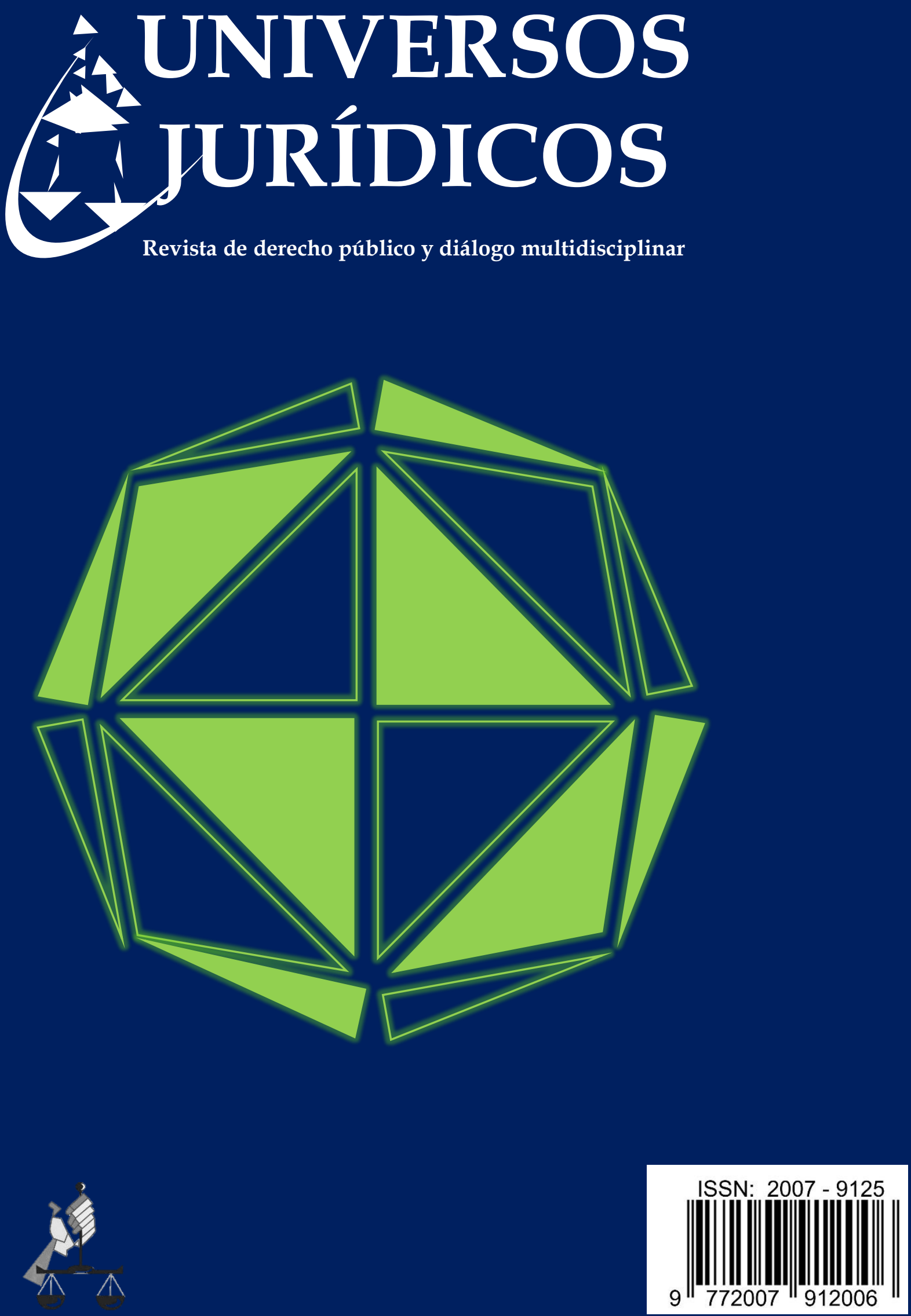


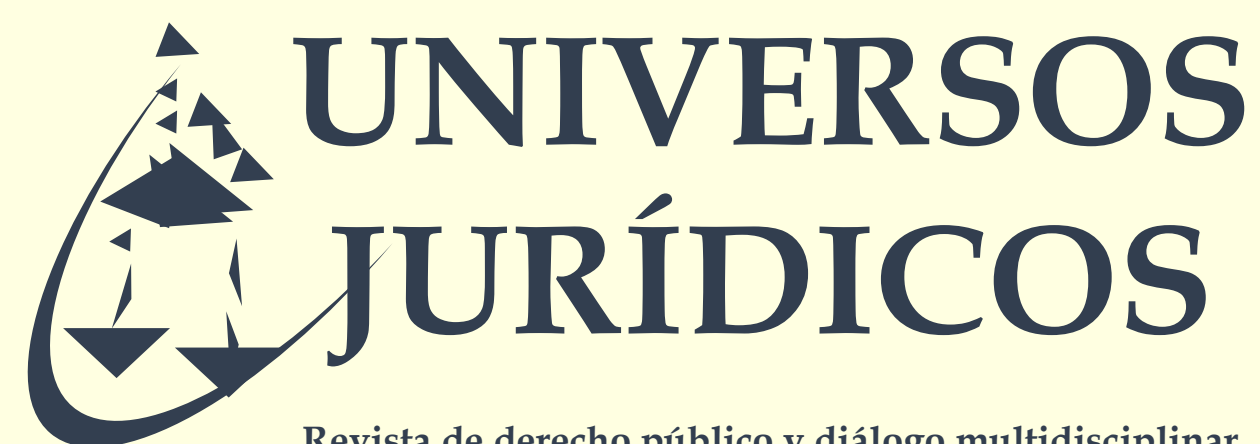

Revista de derecho público y diálogo multidisciplinar

\section{PÁGINA LEGAL}

Universos Jurídicos, año 6, No. 11, noviembre 2018-abril 2019, es una publicación semestral editada por la Universidad Veracruzana a través del Instituto de Investigaciones Jurídicas. Lomas del estadio S/N, col. Centro. C.P. 91000. Xalapa, Veracruz, México. Teléfono +52 (228)8186841. http://www.uv.mx/iij, fabaez@uv.mx. Reserva de Derechos al uso exclusivo No. 04-2013-041509530000-203, ISSN 2007-9125, Ambos otorgados por el Instituto Nacional del Derecho de Autor. Responsable de la última actualización de este número: Instituto de Investigaciones Jurídicas, calle Hermenegildo Galeana esquina 7 de Noviembre S/N, Zona Centro, C.P. 91000. Fecha de la última modificación de este número: 04 de Noviembre de 2018.

Las opiniones expresadas por los autores no necesariamente reflejan la postura del editor de la publicación.

Queda prohibida la reproducción total o parcial de los contenidos e imágenes de la publicación sin previa autorización de la Universidad Veracruzana. 


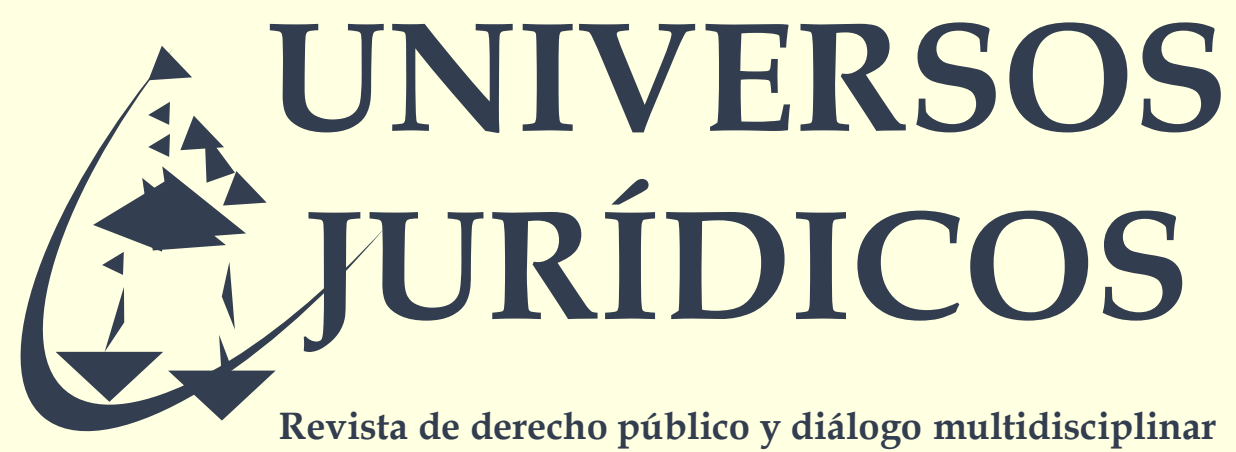

Directora del Instituto de Investigaciones Jurídicas

Petra Armenta Ramírez

Director de la Revista Universos Jurídicos

José Francisco Báez Corona

\section{Consejo Editorial}

Andre Braen (Université d'Ottawa, Canadá)

Ariadna Estévez López (Universidad Nacional Autónoma de México, México)

Carlos Báez Silva (Escuela Libre de Derecho, México)

David Cienfuegos Salgado (Universidad Nacional Autónoma de México, México)

Gloria del Castillo Alemán (Facultad Latinoamericana de Ciencias Sociales, México)

Jaqueline del Carmen Jongitud Zamora (Universidad Veracruzana, México)

José Francisco Báez Corona (Universidad Veracruzana, México)

Luis Daniel Vázquez Valencia (Facultad Latinoamericana de Ciencias Sociales, México)

Luis Ignacio Gordillo Pérez (Universidad de Deusto, España)

Miguel Carbonell (Universidad Nacional Autónoma de México, México)

Miriam de los Ángeles Díaz Córdoba (Universidad Veracruzana, México)

Orisell Richards Martínez (Universidad de la Habana, Cuba)

Petra Armenta Ramírez (Universidad Veracruzana, México)

Yesenia del Carmen Trejo Cruz (Universidad Veracruzana, México)

\section{Diseño y formación editorial}

María del Rocío Viveros Hernández (Universidad Veracruzana, México)

Karina Nohemí Martínez Meza (Universidad Veracruzana, México)

Stefany Lizeth Hernández Ortega (Universidad Veracruzana, México)

\section{Imagen de portada}

Recuperada de internet, utilizada al amparo del artículo 148 de la Ley Federal de Derechos de Autor en México, el cual permite la reproducción de fotografías e ilustraciones difundidos por cualquier medio, si esto no hubiese sido expresamente prohibido por el titular del derecho o el autor no aparece identificado en la misma. 


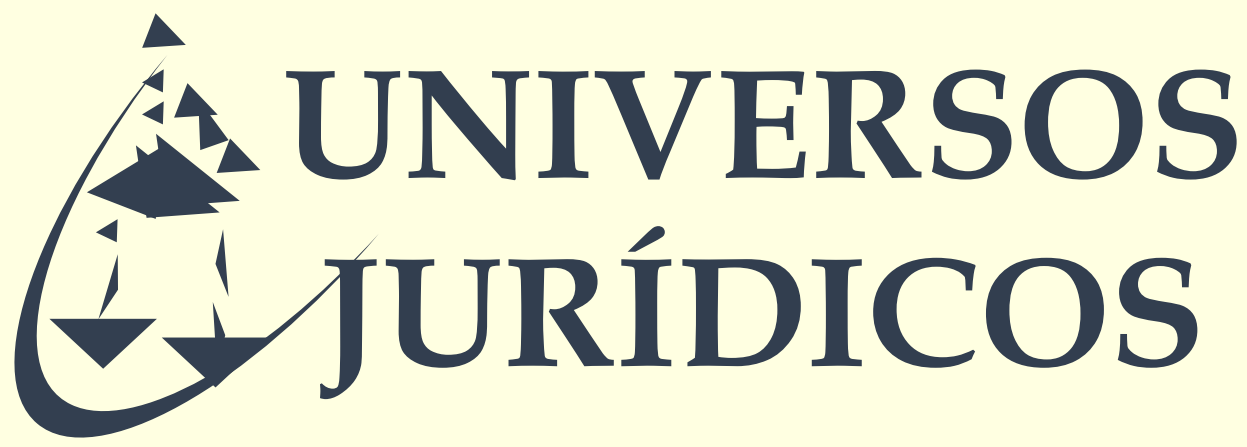

Revista de derecho público y diálogo multidisciplinar

\section{CONTENIDO}

REVISTA POR LAS GENERACIONES DE DERECHOS FUNDAMENTALES

Cedma González Andrade

EL DESPLAZAMIENTO INTERNO FORZADO EN MÉXICO: INDÍGENAS, LAS VÍCTIMAS INVISIBLES

Paola Nayeli Huerta Rodríguez

DERECHO Y GOBERNANZA MUNICIPAL. UN

ESTUDIO DIAGNÓSTICO A TRAVÉS DE LA

CONSULTA POPULAR

José Rubén Croda Marini

LOS OBSTÁCULOS QUE HA ENFRENTADO LA MUJER PARA OCUPAR UN CARGO DE ELECCIÓN POPULAR EN MÉXICO

Lauro Ruiz Méndez

EL PROTOCOLO CONTRA EL ACOSO ESCOLAR EN VERACRUZ

Emilio Fernández Pérez 